Revue d'histoire de l'Amérique française

REVUE D.HISTOIRE DE L'AMÉRIQUE FRANÇAISE

\title{
Bougainville à la lumière de ses lectures : les références classiques dans les Écrits sur le Canada
}

\section{Jean-Olivier Richard}

Volume 64, numéro 2, automne 2010

URI : https://id.erudit.org/iderudit/1017837ar

DOI : https://doi.org/10.7202/1017837ar

Aller au sommaire du numéro

Éditeur(s)

Institut d'histoire de l’Amérique française

ISSN

0035-2357 (imprimé)

1492-1383 (numérique)

Découvrir la revue

Citer cet article

Richard, J.-O. (2010). Bougainville à la lumière de ses lectures : les références classiques dans les Écrits sur le Canada. Revue d'histoire de l'Amérique française, 64(2), 5-31. https://doi.org/10.7202/1017837ar
Résumé de l'article

La valeur historique du témoignage de Bougainville sur le Canada durant la guerre de Sept Ans est reconnue, mais historiens et biographes ont peu cherché à mettre en lumière la façon dont différents genres littéraires en colorent le contenu. Cette étude démontre l'importance d'expliciter la rhétorique et la culture classique de Bougainville dans les Écrits sur le Canada, plus particulièrement en ce qui concerne les observations « ethnographiques » de l'officier, sa représentation de lui-même et de l'armée française, de même que sa critique de l'administration coloniale. 


\title{
Bougainville à la lumière de ses lectures : les références classiques dans les Écrits sur le Canada
}

\author{
JeAN-Olivier Richard \\ Département d'histoire des sciences et de la technologie \\ Université Johns Hopkins
}

RÉSUMÉ - La valeur historique du témoignage de Bougainville sur le Canada durant la guerre de Sept Ans est reconnue, mais historiens et biographes ont peu cherché à mettre en lumière la façon dont différents genres littéraires en colorent le contenu. Cette étude démontre l'importance d'expliciter la rhétorique et la culture classique de Bougainville dans les Écrits sur le Canada, plus particulièrement en ce qui concerne les observations « ethnographiques» de l'officier, sa représentation de lui-même et de l'armée française, de même que sa critique de l'administration coloniale.

ABStract - The historical value of Bougainville's testimony on Canada during the Seven Years' War is well recognized, but historians and biographers have generally not appreciated the extent to which various literary genres color its content. This study shows the importance of making the rhetoric and classical culture of Bougainville explicit in the Écrits sur le Canada, in particular with respect to the officer's «ethnographic » observations, his representation of himself and the French army, and his critique of the colonial administration.

L a grande majorité des ouvrages portant sur Louis-Antoine de Bougainville (1729-1811) mettent l'accent sur son épopée maritime, les excellents travaux d'Étienne Taillemite et de Jean-Étienne Martin-Allanic faisant à cet égard figures de proue ${ }^{1}$. Il est vrai que plusieurs biographes

1. Étienne Taillemite, Bougainville et ses compagnons autour du monde 1766-1769 (Paris, Imprimerie Nationale, 1977), 2 vol., 516 p., 579 p. ; Jean-Étienne Martin-Allanic, Bougainville: Navigateur et les découvertes de son temps (Paris, Presses universitaires de France, 1964), 2 vol, 1600 p. 
détaillent son passage au Canada², mais la plupart racontent la jeunesse d'un personnage plus romantique qu'historique, imaginé à la lumière du "philosophe» que laissent entrevoir les pages de son Voyage autour $d u$ monde $e^{3}$. À l'exception de Michael Ross, qui souligne le fait que l'épisode tahitien fait beaucoup d'ombre ${ }^{4}$, tous semblent privilégier les aventures de Bougainville le navigateur à celles de Bougainville le militaire.

De leur côté, les historiens de la Nouvelle-France apprécient pleinement la valeur historique des Écrits sur le Canada5. Tant sur le plan de l'histoire militaire que de l'histoire coloniale, le témoignage de Bougainville ouvre une fenêtre précieuse sur la fin du Régime français en Amérique du Nord. Il n'en demeure pas moins, cependant, que la plupart des historiens ont abordé les mémoires, le journal et les lettres de Bougainville comme autant de filons à exploiter, plutôt que comme le travail d'un écrivain. Nous croyons que cette approche ne rend pas justice aux textes ${ }^{6}$. Même si les Écrits n'ont pas été publiés du temps de Bougainville et qu'ils ne constituent pas une œuvre à proprement parler, ils sont néanmoins issus d'une tête remplie d'aspirations philosophiques et littéraires. Il semble impor-

2. À titre d'exemples, voir René de Kerralain, Les Français au Canada: la jeunesse de Bougainville et la guerre de Sept Ans (Paris, Nogent-le-Rotrou, 1896), 190 p.; Jean Le Franc, Bougainville et ses compagnons (Paris, Albin Michel, 1929), 253 p. ; Mary Kimbrough, Louis-Antoine de Bougainville, 1729-1811: A Study in French Naval History and Politics (Lewiston, E. Mellen Press, 1990), 241 p.; Thierry Boissel, Bougainville, ou, L'homme de l'univers (Paris, Olivier Orban, 1991), 266 p. ; Victor Suthren, The Sea Has No End (Toronto, The Dundurn Group, 2004), 216 p. ; John Dunmore, Storms and Dreams (Fairbanks, University of Alaska Press, 2007), 296 p.

3. Louis Antoine de Bougainville, Voyage autour du monde : par la frégate du Roi la Boudeuse et la flûte L’Étoile, Jacques Proust, dir. (Paris, Gallimard, 1982), 477 p. Voir aussi Denis Diderot, Le Supplément au voyage de Bougainville (Paris, Gallimard, 2002), 182 p., ouvrage qui influence évidemment cette lecture "téléologique». Nous sommes redevable des articles de Benoît Melançon et d'Emmanuel Bouchard et Réal Ouellet (infra), qui critiquent cette tendance à interpréter les Écrits à la lumière du Voyage.

4. "The fame, however, of his journey round the world, and particularly of his visit to Tahiti, has almost entirely eclipsed the other brilliant exploits of this truly remarkable man. " Michael Ross, Bougainville (London, Gordon \& Cremonesi, 1978), 9.

5. Louis-Antoine de Bougainville, Écrits sur le Canada: Mémoires, journal, lettres (Sillery, Le Septentrion, 2003), 425 p., deuxième édition. En attendant une édition fidèlement établie des textes de Bougainville, nous travaillerons, pour des raisons de commodité, à partir de l'édition de 2003. L'ouvrage comprend une dizaine de mémoires (1757-1759), le journal de l'expédition d'Amérique (1756-1760), 21 lettres adressées à ses proches (1756-1759) ainsi qu’un index relativement détaillé.

6. Gordon M. Sayre observe, au sujet de ses collègues américains, que les «Historians continue to read these texts, draw facts from them about Indians and colonists' lives, and cite the names of the explorers and missionaries who wrote them, but rarely do they explain what these books look like and how they work as texts. " Il déplore ce qu'il appelle leur "cut and paste method» et croit que ces témoignages "deserve to be read as narrative literature». G. Sayre, Les Sauvages Américains: Representations of Native Americans in French and English Colonial Literature (Chapel Hill, University of Carolina Press, 1997), 2. Bien que l'historiographie canadienne diffère de celle de nos voisins, il semble, prenant Bougainville à témoin, que des lacunes similaires existent de notre côté de la frontière. 
tant, si l'on souhaite évaluer le contenu du témoignage de Bougainville, d'examiner les modes d'expression qui le colorent ${ }^{7}$.

Dans cette étude, nous tâchons de dégager les genres littéraires qui structurent trois facettes importantes des Écrits, nommément, la représentation du Sauvage nord-américain, l'image que Bougainville projette de lui-même en tant qu'officier de l'armée française ainsi que la critique de l'administration coloniale. À la lumière de notre examen, il semble que le jeune officier réfracte son expérience de la colonie en faisant consciemment appel à une variété de traditions littéraires - histoire naturelle et morale, critique philosophique, récit épique, harangue, satire, tragédie ${ }^{8}$ - dont l'usage rhétorique colore ses observations. Davantage que de simples exercices de style, ces passages sont généralement signalés par des références à l'Antiquité païenne s'apparentant à celles que l'on retrouve dans les écrits critiques des philosophes des Lumières. Nous cherchons à déterminer la place qu'occupent ces références (et la culture littéraire en général) chez Bougainville, étape nécessaire si l'on souhaite mieux comprendre son expérience de la colonie. Sans chercher à cantonner l'auteur dans un courant littéraire ou philosophique particulier (par exemple, à la vogue sentimentaliste de la seconde moitié du XVIII ${ }^{e}$ siècle, dont on sent l'influence sur le plan stylistique ${ }^{9}$ ), ce sont les lectures auxquelles il fait lui-même référence qui nous servent de point de départ.

7. Les biographes qui romancent le passage de Bougainville chez les Amérindiens ou qui interprètent le texte sous un angle téléologique démontrent la nécessité d'expliciter la teneur littéraire des Écrits. Pierre Berthiaume offre une analyse fort intéressante du remaniement littéraire auquel Bougainville soumet le journal de bord qu'il a tenu durant son voyage autour du monde, une fois venu le temps de le faire paraître. Sa comparaison des textes nous fait prendre conscience que «le témoignage rapporté dans un récit n'apparaît jamais comme l'expression spontanée d'une expérience, mais comme le résultat d'un travail rédactionnel conscient, pour tout dire, littéraire». Pierre Berthiaume, L'Aventure américaine au XVIII siècle: Du voyage à l'écriture (Ottawa, Presses de l'Université d'Ottawa, 1990), 166. Bien que dans le cas du journal d'expédition d'Amérique, nous ne disposions que de l'ébauche d'une publication qui n'a pas vu le jour, notre analyse montre que les notes de Bougainville, sans être mises en récit, ne constituent pas «l'expression spontanée d'une expérience». En effet, l'écrivain y est déjà à l’œuvre.

8. Il est difficile d'établir des correspondances entre genres et passages spécifiques. Aussi, nous entendons "genres " au sens large de "modes d'expression» ou encore de "traditions littéraires », plutôt que comme des ensembles de conventions littéraires rigides. Louise Dechêne analyse la représentation du soldat canadien sous le Régime français de façon analogue, dégageant différents "modèles» qui ont inspiré le mythe du milicien; voir chez cette auteure, Le peuple, l'État et la guerre au Canada sous le régime français, Hélène Paré, Sylvie Dépatie, Catherine Desbarats et Thomas Wien, dir. (Montréal, Éditions du Boréal, 2008), 61-91. Voir également Marie-Chrisitine Pioffet, La tentation de l'épopée dans les relations des Jésuites (Sillery, Le Septentrion, 1997), 300 p., qui offre un autre modèle intéressant.

9. Le sentimentalisme littéraire se manifeste surtout dans le vocabulaire des lettres et des passages du journal où Bougainville se présente comme une victime, verse des larmes sur son sort et exprime son amitié par des effusions de tendresse. À cela on pourrait ajouter l'influence d'un sentimentalisme philosophique se rapportant à l'étude de la nature et des mœurs (voir note 21). 


\section{ETHNOGRAPHIE ET RHÉTORIQUE}

Un vide reste à combler dans les études sur Bougainville en ce qui a trait aux observations ethnographiques nord-américaines que l'officier disperse au fil des pages de ses Écrits. Éparses et en apparence superficielles, parfois élogieuses, parfois méprisantes, ces observations ont longtemps été délaissées des historiens jugeant le tableau d'ensemble moins révélateur des populations autochtones de l'époque que de l'auteur lui-même. Ironiquement, le traitement de surface qui en a résulté dénature les intentions du jeune officier et, conséquemment, l'image qu'on se fait de lui. Au bout du compte, sait-on au juste ce que ces observations révèlent de Bougainville?

Bougainville figure bien à l'index de quelques études majeures sur l'histoire de l'ethnographie, notamment l'Anthropologie et Histoire au siècle des lumières de Michèle Duchet, ou encore L'Amérique et le rêve exotique de Gilbert Chinard ${ }^{10}$. Cependant, loin de diriger leur attention vers les péripéties que le jeune officier relate dans les Écrits, ces auteurs s'intéressent plutôt au Voyage, dont l'épisode tahitien sert de tremplin pour aborder le Supplément de Diderot. Les biographes ont eux aussi souvent lu les observations ethnographiques du jeune Bougainville à la lumière de celles qui se trouvent dans son Voyage ${ }^{11}$.

Dans le but de rectifier cette interprétation téléologique, certains littéraires, prenant le relais des historiens, se sont penchés sur les Écrits avec l'intention de dégager une vision plus juste de ce que Bougainville a pu penser du Sauvage. Ainsi, en se basant sur les lettres de Bougainville, Benoît Melançon argue que «la curiosité que l'on prête si généreusement à Bougainville paraît être subordonnée à des visées pragmatiques ponctuelles: ne pas abandonner la course aux distinctions académiques, se rappeler au bon souvenir de sa famille adoptive ${ }^{12}$ ». Si l'officier établit quelques comparaisons flatteuses entre Amérindiens et héros de l'Antiquité, c'est d'abord pour se "peindre lui-même» plutôt que par curiosité

10. Michèle Duchet, Anthropologie et Histoire au siècle des lumières (Paris, Albin Michel, 1995), 611 p. ; Gilbert Chinard, L'Amérique et le rêve exotique dans la littérature française au XVII et au XVIII siècles (Paris, Librairie E. Droz, 1934), 374-379.

11. Benoît Melançon, «Bougainville avant Tahiti: les Amérindiens dans la correspondance canadienne (1756-1760)", dans Georges Bérubé et Marie-France Silver, dir., La lettre au XVIII siècle et ses avatars: Actes du Colloque international tenu au Collège universitaire Glendon, Université York; Toronto (Ontario) Canada, 29

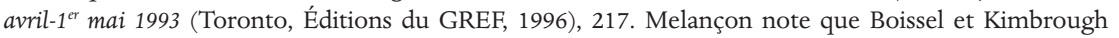
tombent tous deux dans ce piège. Voir aussi, du même auteur, «Les limites du dialogue: Lahontan, les jésuites, Bougainville», dans Jean Marie Goulemot, dir., Dialogisme culturel au XVIII siècle: actes (Tour, Université de Tour, 1997), 15-30.

12. B. Melançon, «Bougainville avant Tahiti...», op. cit., 222. 
ou souci ethnographique ${ }^{13}$. Dans une note de bas de page, Melançon rappelle aussi que le journal et les mémoires étaient destinés au ministre de la Marine, et donc indirectement au Roi ${ }^{14}$. Bougainville aura sans doute voulu flatter son audience en étalant son érudition, sa "culture livresque». L'auteur soutient également que les passages qui expriment plus ouvertement le dégoût de l'officier face aux horreurs perpétrées par ses alliés amérindiens sont plus représentatifs de sa perception du Sauvage: «Exil et monstres: ces deux mots, Bougainville les utilise fort souvent pour parler de sa situation. Plutôt que de souligner sa curiosité, ils montrent assez sa façon de réagir aux actions des Amérindiens et son état d'esprit au Canada ${ }^{15}$.»

Emmanuel Bouchard et Réal Ouellet affirment quant à eux, avec raison, que «les textes sur le Canada ne sauraient constituer à proprement parler une ethnographie du Sauvage américain». Ils considèrent ainsi les "nombreux passages sur les mœurs et le caractère des Sauvages» comme des "remarques peu développées qu'il répète ici et là, au fil de sa narration ${ }^{16}$ ". Selon eux, les nombreuses comparaisons avec l'Antiquité que l'on trouve dans les Écrits "révèlent une culture livresque certaine; mais elles ne constituent pas, en raison de leur imprécision et de leur superficialité, un embryon de réflexion philosophique ou d'anthropologie comparée. Elles paraissent plutôt avoir une simple valeur ornementale ${ }^{17}$. " $S^{\prime}$ ils admettent "[qu'] on ne saurait négliger le courant philosophique dans lequel se situe Bougainville», ces auteurs concluent néanmoins que «la bonne volonté du "philosophe" ", telle qu'il l'exprime à quelques occasions au début de son séjour au Canada, "s'émoussera vite» face aux horreurs de la guerre à l'amérindienne ${ }^{18}$.

Ces interprétations ne sont pas à exclure, mais sont-elles suffisantes? Les observations ethnographiques de Bougainville, en particulier

13. Melançon cite l'extrait suivant à titre d'exemple: «[E]n vérité, les sauvages sont, à peu de choses près, les Grecs d'Homère. J'ai retrouvé Achille, Ajax, Ulysse, Nestor, Calcas, mais tout crachés. Nous avons bien aussi quelques Didons, mais on ne se boude pas pour elles. Ce n'est pas qu'elles n'en vaillent pas la peine; mais nous ne sommes ni jaloux ni exclusifs.» (L.-A. de Bougainville, EC, op. cit., 386). Insérée dans une lettre par ailleurs «hostile» aux Amérindiens, cette comparaison détonne. L'auteur explique cette contradiction apparente en suggérant que «les Amérindiens, devenus héros grecs, servent de fairevaloir à l'épistolier», B. Melançon, «Bougainville avant Tahiti... », op. cit., 225-226.

14. Ibid., 226.

15. Ibid., 222.

16. Emmanuel Bouchard et Réal Ouellet, "Sauvages du Canada et du Pacifique chez Bougainville», Revista Española de Estudios Canadienses, 3,2 (1997): 9.

17. Ibid., 16.

18. Ibid., 17. 
lorsqu'elles se manifestent par des parallèles avec l'Antiquité, sont certes à la fois instrumentales et ornementales. Notre examen des textes dévoile cependant un éventail de remarques plus riches que l'analyse de ces auteurs ne le laisse entendre. Ces remarques vont d'une appréciation prosaïque des forces de ses alliés jusqu'aux représentations les plus dramatiques, en passant par toute une gamme de commentaires ethnographiques qui, s'ils «ne constituent pas un embryon... d'anthropologie comparée", s'insèrent toutefois au sein d'une tradition d'histoire naturelle et morale plus souple que l'ethnographie. En effet, le terme «ethnographie», que nous utilisons parce que commode, est un anachronisme qui ne rend peut-être pas justice à cette tradition. Abordées comme des conventions d'histoire naturelle et morale, les comparaisons littéraires et exagérations rhétoriques des Écrits se révèlent à la fois comme l'expression de ce qu'il conviendrait d'appeler, suivant Jessica Riskin, le «sentimentalisme empirique» des Lumières françaises ${ }^{19}$, de même que comme des tentatives de critiques morales, en particulier à l'endroit des superstitions et des croyances religieuses des Autochtones. Notre examen révèle ainsi une attitude typiquement philosophique, non pas celle d'un esprit "curieux de tout», comme certains l'ont supposée ${ }^{20}$, ni celle d'un philosophe radical, mais bien celle d'un moderne ancré dans la tradition humaniste, usant de l'ornement et de l'émotion pour habiller un discours critique, et témoignant de ses expériences au travers d'une réappropriation de son héritage classique ${ }^{21}$.

19. Au travers de six épisodes et controverses philosophiques (scientifiques) du siècle des Lumières, Riskin montre que le courant sentimentaliste, généralement associé aux lettres, a nourri et s'est nourri en retour de l'empirisme philosophique de plusieurs philosophes, pour qui la perception sensorielle et les sentiments qui en résultent constituaient en soi une voie d'accès à la connaissance. Si Riskin ne fait qu'effleurer l'histoire naturelle et morale dans son étude, c'est parce que cette discipline, par son champ d'étude "panoramique», sa méthodologie et sa forme narrative, se prête manifestement bien au sentimentalisme; il convient plutôt, selon l'auteure, d'insister sur les champs d'études philosophiques (scientifiques) qu'on n'imaginerait pas de nos jours susceptibles d'être empreints de sentimentalisme. Jessica Riskin, Science in the Age of Sensibility: The Sentimental Empiricists of the French Enlightenment (Chicago, University of Chicago Press, 2002), 7.

20. T. Boissel, Bougainville..., op. cit., 13, cité dans B. Melançon, «Bougainville avant Tahiti...», op. cit., 217.

21. En d'autres termes, on remarque chez Bougainville une attitude philosophique qui s'apparente à celle que Peter Gay identifie dans The Enlightenment : An Interpretation. Gay soutient que les philosophes formaient en quelque sorte une famille de "païens modernes» (modern pagans), œuvrant de façon plus ou moins concertée pour l'avancement d'un idéal de modernité, critiquant les institutions politiques et religieuses de l'époque par le truchement d'une réappropriation de leur héritage classique. Les écrits des Anciens leur fournissaient des «modèles illustres» (illustrious models) de vertu et d'éloquence, de même que des "prédécesseurs respectables " (a respectable ancestry) dont ils pouvaient sans honte suivre l'exemple. Peter Gay, The Enlightenment: An Interpretation (New York, Knopf, 1966-1969), 2 vol., 107-108. Si l'on devait inclure Bougainville parmi les philosophes, il ferait sans doute partie du groupe d'humanistes éclairés que Jonathan Israël situe entre celui des penseurs radicaux et celui de leurs opposants conservateurs, 
La représentation du Sauvage chez Bougainville est complexe. Son appréciation la plus objective se trouve probablement là où il décrit les Amérindiens comme des troupes auxiliaires indispensables. Leur alliance avec l'armée française doit à tout prix être préservée, affirme-t-il, au risque de les voir changer de camp et prendre parti pour les colons anglais: "calculateurs, politiques et avides, peut-on se flatter qu' ils restent constamment attachés au parti excessivement le plus faible et qui n'aura peut-être rien à leur donner ${ }^{22}$ ?» Bien que Bougainville n'aime pas les mœurs guerrières des Amérindiens, il en mesure pleinement les avantages et les inconvénients: «[L]es Sauvages, admirables dans les bois, de la plus grande expédition contre une troupe qui s'ébranle et cède, avantageux pour le succès de toute autre espèce de guerre, peu propres à la défensive, s'abattent aisément et profondément; dans l'infortune n'ont point le courage de constance ${ }^{23}$. Certes, il se réjouit de la victoire française à Carillon, en 1758, et il se flatte que cette bataille décisive ait été gagnée pratiquement sans l'aide des Sauvages contre un ennemi cinq fois plus nombreux. Cependant, il n'attribue pas naïvement l'heureuse tournure des événements à la seule valeur des soldats ou des officiers ${ }^{24}$. Bougainville y voit un coup de chance et estime que la fortune ne sourira pas aux Français encore longtemps sans le soutien des Autochtones, dont la connaissance du terrain et les talents d'éclaireurs représentent des atouts stratégiques majeurs. Aussi, dans un mémoire qu'il rédige quelques mois après le siège de Carillon, il inclut le ravitaillement en marchandises visant à consolider l'amitié avec les Amérindiens au rang des plus strictes nécessités ${ }^{25}$.

L'«indispensabilité» des Amérindiens est un fardeau, d'autant plus que ces derniers sont conscients de peser lourd dans la balance. Bougainville les décrit parfois comme des gens capricieux, indociles et insolents, pourvus d'un sens de l'honneur louable en soi, mais malheureusement entaché d'orgueil et d'amour-propre excessif : «l'amour-propre est de tous les mondes et l'orgueil est la seule richesse de tout Sauvage», à un tel point que "parmi ces peuples, la plus petite altercation devient une querelle de

dans Radical Enlightenment. Philosophy and the Making of Modernity, 1650-1750, (New York, Oxford University Press, 2001), 832 p. Notez que notre objectif n'est pas de déterminer si le jeune Bougainville mérite sa place parmi les philosophes, mais plutôt de montrer qu’il emploie des stratégies rhétoriques similaires.

22. L.-A. de Bougainville, EC, op. cit., 21.

23. Id.

24. Ibid., 286.

25. Ibid., 26. 
la plus grande conséquence et qui ne finit plus ${ }^{26}$ \%. Leur amour de la liberté et de l'eau-de-vie les conduit à des excès et des abus de toutes sortes, et Bougainville déplore les vols et les meurtres qu'ils commettent sous l'influence de l'alcool. Leurs victimes principales, après les Anglois, sont le bétail et la volaille, de même que les réserves des officiers français, qu'ils ne se gênent pas pour piller lorsqu'ils jugent mériter davantage que ce que le Roi leur accorde ${ }^{27}$. Comme si les coûts matériels encourus ne suffisaient pas, Bougainville s'inquiète de voir la paresse et l'indiscipline des guerriers autochtones gagner les troupes régulières, tout comme elles ont déjà infecté les Canadiens ${ }^{28}$ !

L'irritation et la méfiance de Bougainville, il est vrai, tournent à l'indignation et à la consternation lorsqu'il est témoin du traitement que certains Sauvages réservent à leurs prisonniers: «Le rhum qui était dans les berges et que les Sauvages ont bu sur-le-champ leur a fait faire de grandes cruautés. Ils ont mis à la chaudière et mangé trois prisonniers; d'autres seront peut-être traités de même. Tous sont esclaves, à moins qu'on ne les rachète; spectacle horrible aux yeux d'un Européen ${ }^{29}$." La levée des chevelures, la torture, le cannibalisme ${ }^{30}$ : voilà des mœurs «barbares» qui lui font regretter la France: "Puisse la mémoire de ces abominations s'éteindre! Quelle terre! Quels peuples! Mon exil durera-t-il encore longtemps $^{31}$ ?» La guerre à l'amérindienne aura été un choc pour le jeune officier entraîné à l'européenne; tout aussi troublante aura été sa prise de conscience qu'on se désensibilise à ses horreurs: «Les cruautés et l'insolence de ces barbares font horreur et répandent du noir dans l'âme. C'est une abominable façon de faire la guerre, la représaille [sic] est effrayante et l'air qu'on respire ici est contagieux pour l'accoutumance à l'insensibilitéc ${ }^{32}$.»

Le ton dramatique de ces passages retient notre attention. Est-il logique de reconnaître une valeur rhétorique ou ornementale aux comparaisons avec les héros grecs, et de soutenir du même coup que les descriptions de

26. Ibid., 150, 188.

27. Ibid., 286.

28. Ibid., 144. Bougainville semble parler de l'air canadien «imprégné d'indépendance» comme d'un air vicié.

29. Ibid., 209.

30. Bougainville sait que le cannibalisme n’était pas pratiqué par tous les peuples amérindiens, mais ne semble pas saisir jusqu'à quel point la chair humaine les répugne. Comparez avec le témoignage plus objectif de Pierre Pouchot sur l'anthropophagie rituelle dans Mémoire sur la dernière guerre de l'Amérique septentrionale (Sillery, Le Septentrion, 2003), 299. Pouchot affirme que c'est à contrecœur que le Sauvage s'adonne à cette pratique.

31. L.-A. de Bougainville, EC, op. cit., 393.

32. Ibid., 137. 
Sauvages monstrueux sont plus représentatives des états d'âme de Bougainville? Après tout, nulle part dans les Écrits ne trouve-t-on plus de tournures rhétoriques que lorsque l'auteur s'abandonne à l'écriture:

1800 sauvages, nus, noirs, rouges, rugissant, mugissant, dansant, chantant la guerre, s'enivrant, demandant du bouillon, c'est-à-dire du sang, attirés de 500 lieues par l'odeur de la chair fraîche et l'occasion d'apprendre à leur jeunesse comment on découpe un humain destiné à la chaudière. Voilà nos camarades qui jour et nuit sont notre ombre. Je frémis des spectacles affreux qu'ils nous préparent ${ }^{33}$.

Pathos dramatique, figures de style, langage connoté : cet extrait vise à laisser une vive impression sur le lecteur. Lorsque le style de Bougainville verse dans le sentimentalisme, son propos philosophique ne s'en trouve pas pour autant vide de sens. Bien au contraire, l'histoire naturelle et morale du Sauvage se raconte particulièrement bien par le sentiment et les descriptions vives: l'expérience que Bougainville acquiert de ses propres yeux, il tâche de la transmettre dans une narration susceptible de plaire, d'exciter les passions, voire d'arracher quelques larmes. S'il peut sembler que l'idée du Sauvage monstrueux et cruel prévaut dans les Écrits (et donc dans l'esprit de l'auteur), c'est ironiquement parce que les passages qui renforcent cette idée sont plus vifs, plus susceptibles de frapper l'imagination que les observations «ethnographiques» plus flatteuses et plus convenues.

Passons en revue ces dites observations. Outre la comparaison avec les héros de Homère, on trouve toute une variété de notes sur les mœurs des Amérindiens, doublées de parallèles avec l'Antiquité classique ${ }^{34}$. En faisant usage de tels "classicismes", Bougainville s'insère au sein d'une longue tradition d'histoire naturelle et morale qui remonte aux premiers contacts entre les habitants du Nouveau Monde et les Européens. On sait qu'aux $\mathrm{XV}^{\mathrm{e}}$ et $\mathrm{XVI}^{\mathrm{e}}$ siècles, explorateurs et autres témoins se sont d'abord rabattus sur des catégories classiques familières pour mettre de l'ordre dans un

33. Ibid., 374.

34. Nous comptons une soixantaine de références à l'Antiquité classique dans les Écrits, dont 54 distribuées au fil des 250 pages du journal de campagne. Il est vrai que ce peut sembler peu en comparaison des écrits des Diderot et autres Rousseau de son temps. Cela dit, une fois mis en parallèle avec les journaux et les lettres d'autres officiers français comme Pouchot, Lévis et même Montcalm (où il faut être prudent et soustraire les sections recopiées du journal de Bougainville), les Écrits paraissent regorger de références aux classiques, que ce soit sous forme de locutions latines proverbiales, de comparaisons ethnographiques ou de parallèles historiques. Les références aux auteurs modernes sont moins fréquentes mais tout de même nombreuses. Chez les anciens, il cite ou évoque César, Cicéron, Hérodote, Homère, Horace, Juvénal, Lucien, Ovide, Tacite, Virgile et Xénophon; chez les modernes, Bayle, Charlevoix, Corneille, Fontenelle, Lafitau, Montaigne, Montesquieu, Newton, Rabelais et Rousseau. 
chaos de nouvelles expériences ${ }^{35}$. Ainsi, on note très tôt dans la littérature de voyage des comparaisons entre le corps idéalisé de la statue grecque et le corps des Sauvages - tous deux grands, imberbes, nus et gracieux des comparaisons qui cèdent peu à peu leur place à des analogies moins superficielles, basées sur l'observation des mœurs de ces peuples. On trouve de distants échos de ces motifs dans la première description que Bougainville fait des Autochtones ${ }^{36}$, et tout comme les premiers «ethnographes", l'officier aiguise ses observations au fur et à mesure qu'il s'habitue aux Amérindiens:

Ils sont nus à l'exception du brayet, se matachent de noir, de rouge, de bleu, etc.; leur tête est rasée; des plumes en font l'ornement. Dans leurs oreilles allongées sont des anneaux de fils de laiton. Ils ont pour couvertes des peaux de castor et des loups illinois. Ils portent des lances, des flèches et des carquois faits de peaux de bêtes. Chaque bande va danser à son tour devant les maisons des principaux de la ville: en vérité leurs danses ressemblent à la pyrrhique et à ces autres danses guerrières des Grecs. J'ai trouvé quelques différences dans l'orchestre des Puans et des Outaouais; à cette espèce de tambourin par lequel ils marquent la cadence se joignent les voix de quelques hommes et de quelques femmes et le tout forme des accords assez harmonieux. Au reste ces Sauvages sont droits, bien faits, et presque tous de la grande taille. Ils ont des cabanes sous les murs de la ville. Ils y passent les nuits à boire et à chanter ${ }^{37}$.

Dans un même ordre d'idées, il observe que les Autochtones font le décompte des morts à la fin des batailles d'une façon similaire à celle des Perses $^{38}$; ou encore que le rôle des femmes dans les conseils de guerre s'apparente à celui des matrones romaines ${ }^{39}$. Le jeune officier utilise en outre bon nombre de locutions latines lorsqu'il décrit les relations entre les Amérindiens et les Français, des locutions qui encapsulent des idées

35. On pense à Pierre Martyr d'Anghiera, de Acosta, Oviedo et autres Las Casas, pour n'en nommer que quelques-uns. Pour une histoire de la réception européenne du Nouveau Monde en termes de catégories classiques, voir J. H. Elliott, The Old World and the New 1492-1650 (Cambridge, Cambridge University Press, 1970), 118 p., chap. 1 et 2 en particulier. Voir aussi Margaret T. Hodgen, Early Anthropology in the Sixteenth and Seventeenth Centuries (Philadelphie, University of Pennsylvania Press, 1964), 523 p., et Arnaud Decroix, "Les références à l'Antiquité dans la description des peuples autochtones du Canada au XVIII ${ }^{\mathrm{e}}$ siècle», dans Personne et Res Publica (Paris, L’Harmattan, 2008), 11: 69-83.

36. L.-A. de Bougainville, EC, op. cit., 109.

37. Ibid., 191.

38. Ibid., 201.

39. Ibid., 181. 
complexes qu'il n'a pas le temps ou le désir de développer dans son journal ${ }^{40}$.

Mais Bougainville ne fait pas que réitérer les platitudes d'un discours usé. De la même façon qu'il exprime, par le truchement rhétorique du Sauvage monstrueux, le «choc culturel» qu'il éprouve au contact de ses alliés amérindiens, Bougainville emprunte certaines conventions d'histoire naturelle et morale pour structurer une critique à leur endroit. Une facette importante de cette appropriation est l'établissement de comparaisons entre les mœurs et croyances spirituelles de différents peuples, comparaisons qui renvoient souvent au christianisme et à la "superstition" religieuse $^{41}$. En cela, Bougainville s'insère à la fois dans la tradition humaniste et le courant philosophique des Lumières. En effet, une rhétorique chargée voit le jour dans les écrits des humanistes, missionnaires, utopistes et philosophes du XVI ${ }^{e}, \mathrm{XVII}^{\mathrm{e}}$ et $\mathrm{XVIII}{ }^{\mathrm{e}}$ siècle ${ }^{42}$, allant de la critique implicite du barbarisme européen chez Montaigne, dans son essai sur les "Cannibales», jusqu'à la remise en question radicale des autorités religieuses et politiques par Lahontan, Fontenelle et Rousseau, en passant bien sûr par l'apologétique des jésuites de Le Jeune, Brébeuf, puis Lafitau et Charlevoix.

Dans une longue note où il décrit la religion des Sauvages des Pays d'en haut (région des Grands Lacs), Bougainville qualifie leurs croyances de "paganisme brut et encore dans son enfance», une sorte d'animisme dans le cadre duquel le Sauvage "se fait un dieu de l'objet qui le frappe: le soleil, la lune, les étoiles, un serpent, un orignal, enfin tous les êtres visibles

40. Par exemple, la victoire française à Chouagen et l'impact positif que les rumeurs de triomphes ont sur les Sauvages lui rappellent Ovide: «Donec eris felix, multos numerabis amicos. Tempora si fuerint nubila, solus eris » [Tant que tu auras de la chance, tes amis seront nombreux; si le temps se couvre, tu te retrouveras seul, Tristia I,9,5 ] Ibid., 149.

41. Voir, à titre d'exemple, l'essai éclairant de Julie Boch, «L'Occident au miroir des sauvages: figures du païen chez Fontenelle et Lafitau ", Tangence, 72 (2003): 75-91, en ligne, Érudit. http:/ /id.erudit.org/ iderudit/009093ar [consulté le 3 septembre 2011]. Bloch compare De l'origine des fables (1724) de Fontenelle aux Mœurs des sauvages américains comparées aux mours des premiers temps (1724) de Lafitau, et montre comment ces deux penseurs emploient une méthode comparative similaire afin de défendre des thèses diamétralement opposées sur l'origine des croyances religieuses. D’une part, Fontenelle formule une critique des croyances spirituelles amérindiennes en les comparant avec celles des païens de l'Antiquité, les similitudes trouvées suggérant que les hommes ont de tout temps eu tendance à inventer des fables sur la base de leur expérience des phénomènes naturels. Cette critique a des implications pour le christianisme (ne serait-ce qu'un ensemble de fables?) et constitue un bon exemple de ces critiques à demi dissimulées dont regorgent les écrits des philosophes. D’autre part, Lafitau établit des parallèles similaires afin de montrer que la ressemblance entre les coutumes des Sauvages et celles des barbares de l'Antiquité est le gage d'une commune origine, que Lafitau identifie évidemment comme une révélation universelle et antédiluvienne, corrompue par les peuples au fil du temps. Voir aussi A. Decroix, «Les références à l'antiquité..." op. cit., 69-83.

42. G. Chinard, L'Amérique et le rêve exotique..., op. cit., v-viii, 366-398. 
animés ou inanimés ${ }^{43}$ ». Loin d'être motivé par un culte du primitivisme ${ }^{44}$, Bougainville rationalise le rituel de totémisation des Amérindiens en soulignant, par exemple, que le jeûne préliminaire du rituel est "propre à faire rêver» et à exciter l'imagination. Cette remarque a pour effet de démystifier l'expérience spirituelle en l'apparentant à un état de délire ${ }^{45}$. On peut donc aisément reconnaître une fausse candeur voltairienne lorsque Bougainville décrit la mouche comme le plus heureux des totems: "Heureux quand l'objet de ce rêve important est d'un petit volume, une mouche, par exemple, car alors, mon corps est une mouche, disent-ils, je suis invulnérable; quel homme assez adroit pour attraper un point ${ }^{46}{ }^{\prime}$ Le ton est ironique.

De façon similaire, le paragraphe suivant trahit l'ironie philosophique de l'auteur en rapprochant du christianisme le paganisme des Sauvages tel qu'il a évolué au contact des Européens:

La croyance de deux esprits, l'un bon, l'autre mauvais ; l'un habitant les cieux, l'autre, les entrailles de la terre, établie maintenant parmi eux, ne l'est que depuis qu'ils commercent avec les Européens. Originairement ils ne reconnaissaient que leur Manitou. Au reste ils disent que le maître de la vie qui les a créés était brun et sans barbe tandis que celui qui a créé le Français était blanc et barbu. ${ }^{47}$

Ces observations, suivies d’une citation de Fontenelle ( Si Dieu a fait les hommes à sa ressemblance, les hommes le lui ont bien rendu $\left.{ }^{48} »\right)$, ajoutent à sa critique de la naïveté religieuse de l'Amérindien. Mais en critiquant leurs cultes religieux, il cible par ricochet les chrétiens qui s'accrochent à des croyances similaires. Comme Fontenelle et tant d'autres philosophes éclairés, Bougainville croit que l'être humain a une tendance générale à projeter beaucoup de lui-même dans sa conception du divin. Bougainville fait ainsi son humble part dans la lutte acharnée que les philosophes mènent encore à l'époque contre les superstitions religieuses ${ }^{49}$.

43. L.-A. de Bougainville, EC, op. cit., 201.

44. C'est ce que semble croire Boissel, lorsqu'il écrit, parlant de Bougainville, que «les Indiens ne cessent de l'intriguer... ces peuples demeurent proches de l'état de la nature. C'est avant tout cela qui le fascine», T. Boissel, Bougainville..., op. cit., 13.

45. L.-A. de Bougainville, EC, op. cit., 201.

46. Ibid., 201.

47. Ibid., 201-202.

48. Ibid., 202.

49. Pour une discussion de la bataille contre la superstition menée par les philosophes, voir J. Israel, Radical Enlightenment, op. cit., 359-392 («Fontenelle and the War of the Oracles» et «The Death of the Devil»), de même que Loraine Daston et Katharine Park, "The Enlightenment and the Anti-Marvelous ", dans Wonders and the Order of Nature 1150-1750 (New York, Zone Books, 1998), 329-368. 
Les Écrits sont ponctués de pointes contre la superstition, la plupart signalées par des parallèles avec l'Antiquité. Dès les premières pages de son journal, Bougainville écrit qu' «[u]n jongleur dans la cabane de médecine est exactement la pythonisse sur le trépied ou Canadie [?] évoquant les ombres ${ }^{50}$ ». Cette comparaison montre que Bougainville, à l'instar des philosophes et des missionnaires, n'est pas impressionné par les supposés pouvoirs de ces devins. Avec une touche d'humour noir, il déplore la futilité de leurs pratiques: «Un d'eux, malade, a jonglé qu'il fallait pour le guérir sacrifier un chien. Le chien a été acheté, mis à la chaudière, le festin s'est fait, un sénateur [un vieil Amérindien, avec connotation romaine] a jonglé et le malade se meurt ${ }^{51}$.»

Par ailleurs, les références aux oracles dans les Écrits ne se limitent pas qu'à exprimer le scepticisme de l'auteur face à l'utilité des pratiques religieuses des Sauvages: «Il en est des Sauvages et des interprètes comme des oracles du paganisme auxquels leurs prêtres faisaient dire ce qu'ils jugeaient à propos, ce qui était favorable à leurs intérests [sic], à leurs vues, ou conforme aux désirs de ceux qui les payaient ou qu'ils voulaient flatter ${ }^{52}$.» Les Amérindiens et leurs interprètes ne sont plus représentés ici comme naïfs et superstitieux, mais plutôt comme des manipulateurs. Tout comme les oracles des Grecs et des Romains étaient des charlatans, de la même façon les jongleurs sont-ils trompeurs, usant de leur influence pour leur propre bénéfice. La citation précédente illustre en outre qu'il y a en jeu davantage que l'intégrité des jongleurs. En incluant les interprètes canadiens parmi les oracles, il exprime son scepticisme quant à l'information relayée aux officiers français lors des conseils de guerre amérindiens, scepticisme nourri par sa méfiance envers l'administration coloniale.

Il paraît indéniable que les représentations du Sauvage chez Bougainville, nombreuses et variées, constituent autant de réfractions de la réalité amérindienne. Le portrait dramatique qu'il peint du Sauvage, bien que fondé sur une expérience réelle, n’est pas plus représentatif de son expérience que celui qu'il trace dans ses comparaisons "ethnographiques» avec les peuples de l'Antiquité. Certains historiens ont mis l'accent sur ces dernières, les interprétant comme des signes de la curiosité intellectuelle

50. L.-A. de Bougainville, EC, op. cit., 147. Le point d'interrogation est de l'éditeur. Bougainville fait référence à la sorcière Canidie, dans les Satires de Horace, tout comme Lafitau avant lui dans le premier tome des Mœurs des Sauvages Amériquains (1724), 393. Canadie, sorcière du Canada... coquille ou jeu de mots?

51. Ibid., 303.

52. Ibid., 300. 
de l'auteur, tandis que d'autres, en particulier des littéraires, se sont attardés aux passages qui dépeignent les Autochtones comme des monstres, soulevant ainsi des doutes quant à l'ouverture d'esprit qu'on lui accorde trop facilement. Le fait est que les deux visions se défendent sur la base des textes. Plutôt que d'attribuer ces couleurs aux préjugés, aux penchants larmoyants ou à l'incohérence de Bougainville, nous suggérons qu'il s'agit là de différentes manifestations de l'ambition littéraire de l'auteur, qui s'exerce sciemment à l'histoire naturelle et morale ainsi qu'à la critique philosophique des mœurs.

\section{LA BOUGAINVILLADE: L'EXIL CRUEL ET LA GLORIEUSE RETRAITE}

Un aspect négligé de la réappropriation philosophique des classiques chez Bougainville est son identification avec les héros exemplaires de l'Antiquité. Voyons comment Bougainville se représente dans les Écrits comme un nouvel Énée, et comment il exalte l'armée française en Amérique du Nord en comparant son sort à celui de l'armée grecque de Xénophon. Nous suggérons que Bougainville colore son témoignage en investissant protagonistes et événements de la guerre d'une dimension épique.

D'après Peter Gay, l'identification constitue «the most familiar mode in which the Enlightenment experienced the classical past", comme l'illustre l'impact de l'œuvre de Plutarque sur le caractère de Rousseau, ou encore les fantasmes de Diderot s'imaginant orateur romain ${ }^{53}$. Gay précise cependant que « $[t]$ his sort of adolescent hero-worship... rarely survived into maturity " autrement qu'en tant que "convenient rhetorical device ${ }^{54}$ ». L'identification apparaît comme un mode de réappropriation de l'Antiquité répandu, mais peu significatif ${ }^{55}$.

Nous croyons cependant que l'identification est au cœur du témoignage de Bougainville. Comme Rousseau et Diderot, Bougainville s'identifie à ses héros et se représente comme acteur et témoin d'un drame de proportions épiques. Que Bougainville se soit réellement perçu comme un héros épique ou que sa réappropriation des exemples de l'Antiquité n’ait été pour lui qu'un outil rhétorique, les implications demeurent les mêmes: son témoignage est délibérément projeté dans un cadre littéraire.

L'Énéide de Virgile était l'un des livres préférés de Bougainville ${ }^{56}$. Nous savons qu'il en avait un exemplaire avec lui au Canada et qu'il en cite

53. P. Gay, The Enligthenment..., op. cit., 46.

54. Ibid., 46-47.

55. Ibid., 46.

56. V. Suthren, The Sea..., op. cit., 20. 
régulièrement des extraits ${ }^{57}$. Ses errances en mer, ses combats menés en terres étrangères, son sens du devoir civique et son désir de retrouver sa terre natale font du jeune officier l'héritier tout désigné d'Énée, dont il compare l'exil à son propre séjour au Canada. Ainsi, en décrivant le «massacre» du Fort Guillaume-Henry en 1757, Bougainville fait appel à Virgile : "C'est assez parlé d'horreurs dont je voudrais que le souvenir pût être effacé dans la mémoire de tous les hommes: Heu fuge crudeles terras fuge littus iniquum ${ }^{58}$.» Commentant, un an plus tard, les fortifications qu'il supervise sur l'île au Mouton à la veille du siège de Carillon, il se targue d'être troyen: "si l'ennemi m'eût laissé 15 jours, j'y soutenais le siège de Troie ${ }^{59}$ ". À propos de son périlleux périple le long du SaintLaurent en novembre 1758, il écrit: "C'est le cas de craindre ce qu'on dit: In edit $[$ sic $]$ in Scyllam cupiens vitare Caribdim ", une locution latine commune mais particulièrement apte, dans la mesure où elle évoque le voyage de Virgile aussi bien que le sien ${ }^{60}$.

Sans surprise, une tempête sur l'Atlantique lui inspire des élans de sympathie pour son héros: «Ah! je serais tenté de pardonner à Énée les larmes qu'il verse dans ces tempêtes qu'il essuye. Un héros peut fort bien l'être et avoir peur de se noyer ${ }^{61}$.» Si l'on ajoute à cette liste une liaison avec une Amérindienne (nous notons qu'il parle des Didons du Canada dans une de ses lettres ${ }^{62}$ ); que son père et son meilleur ami meurent tous deux durant son «exil ${ }^{63}$ »; qu'il tâche après la guerre de fonder une colonie avec les restes brisés du peuple acadien ${ }^{64}$; que le Voyage autour $d u$ monde contient également plusieurs références à l'Énéide, notamment sa conclusion "Puppibus et laeti Nautae imposuere coronas ${ }^{65}$ »; il est légitime de croire que Bougainville s'identifie sincèrement à son héros.

L'identification de Bougainville a des implications qui ne sont pas suffisamment reconnues. Dans Bougainville: navigateur et les découvertes de son

57. L.-A. de Bougainville, EC, op. cit., 395.

58. Ibid., 235. «Ô, fuis cette terre cruelle, fuis ce littoral injuste», Aen. III : 44, l'original se lit littus avarum.

59. Ibid., 306.

60. Ibid., 336. On devrait plutôt lire "Incidit in Scyllam cupiens vitare Charybdim», c'est-à-dire, "aller de Charibde en Scylla».

61. Ibid., 342.

62. Ibid., 386.

63. Bougainville mentionne le décès de son père dans sa lettre du 30 juin 1757. Quant à M. Hérault, il meurt en 1759 à la Bataille de Minden, M. Ross, Bougainville..., op. cit., 10.

64. Voir J. Dunmore, Storms and Dreams..., op. cit., 70-140, de même que l'ensemble du premier volume de J.-E. Martin-Allanic, Bougainville: navigateur..., op. cit., pour le détail et le contexte de cette aventure.

65. L.-A. de Bougainville, Voyage..., op. cit., 433. «Et les marins heureux accrochèrent des couronnes à la proue de leurs vaisseaux", Aen. IV : 418. 
temps, Martin-Allanic n'hésite pas à lire les accomplissements tardifs de l'officier à la lumière des aspirations déçues de Jean-Pierre, son frère à la santé fragile qui, au lieu de voyager, étudia la géographie antique. MartinAllanic voit les débats académiques auxquels Jean-Pierre et ses mentors participent comme l’inspiration principale de Bougainville: "Ces études subtiles, ces disputes savantes, ces évocations ardentes dans le passé et dans le présent, tout cela n'était-il point fait pour exciter une vocation chez le jeune Bougainville? Son frère l'y poussait de toute son âme et toute une partie de son discours académique n'avait été qu'un intime et vibrant appel ${ }^{66}$.» L'hypothèse de Martin-Allanic, bien que plausible, ne trouve cependant pas de renfort textuel, alors que la place importante du poème de Virgile dans l'univers mental de Bougainville, aux côtés des autres classiques qui ont nourri son imagination, est facile à établir. Les deux hypothèses ne sont évidemment pas mutuellement exclusives, mais il est nécessaire de souligner la part trop souvent ignorée que joue la figure du héros dans les Écrits.

Sa réappropriation de l'Anabase de Xénophon fournit un autre bon exemple. L'Anabase raconte comment quelque 10000 mercenaires grecs se trouvèrent piégés en Perse au détour d'une défaite. Entourés d'ennemis innombrables, forcés d'entreprendre un voyage périlleux en territoire inconnu à la recherche d'un bras de mer qui les porterait à nouveau en Grèce, ils réussirent, contre toute attente et devant mille dangers, à battre en retraite. Ce haut fait d'armes historique, en partie attribuable à la sagesse de Xénophon (ancien élève de Socrate promu général par la force des choses), constitue à la fois une humiliation pour le roi des Perses et une source de fierté pour les Grecs ${ }^{67}$. Si l'identification de Bougainville avec Xénophon est moins explicite qu'avec Énée, les parallèles qu'il dresse entre la situation précaire mais épique de l’armée française et celle de l'Anabase sont néanmoins révélateurs.

Dans son mémoire du 29 décembre 1758 intitulé «Réflexions sur la campagne prochaine», le jeune officier médite sur la stratégie qu'il souhaiterait voir ses supérieurs adopter advenant la chute de Québec ${ }^{68}$. Bougainville juge qu'une colonie à court de munitions et de vivres, et

66. J.-E. Martin-Allanic, Bougainville: navigateur..., op. cit., 22.

67. Xenophon, The Anabasis of Cyrus, traduction de Wayne Ambler (Ithaca, Cornell University Press, 2008) $281 \mathrm{p}$.

68. L.-A. de Bougainville, $E C$, op. cit., 32. Le titre complet du mémoire: Réflexions sur la campagne prochaine-Examen de cette question: Si Québec est pris le Canada l'est; et de cette autre: si le Canada perdu la France peut soutenir la Louisiane. Dispositions relatives à cet objet. 
assaillie sur trois fronts à la fois, ne pourrait se défendre sans sa capitale administrative et son port principal. Une fois Québec aux mains des Anglais, le Canada en entier devrait selon lui capituler afin d'éviter un bain de sang et le gaspillage inutile des ressources. «L'humanité l'exige, l'intérêt de l'État et celui des colons qui ont bien servi leur prince ${ }^{69}$."

Cette analyse lucide est cependant suivie d'un passage surprenant, dans lequel Bougainville ébauche les plans d'une glorieuse retraite de l'armée française jusqu'en Louisiane, comparable à celle de l'Anabase. Bougainville semble en effet avoir envisagé l'évacuation secrète de 2500 soldats d'élite et d'éclaireurs canadiens chargés de provisions et de pièces d'artillerie. En passant par la porte arrière de la colonie avant la signature des traités, ces troupes échapperaient à des termes humiliants. En suivant le cours des rivières pendant 60 à 70 jours, elles finiraient par atteindre la Louisiane, qu'il faudrait ensuite fortifier et défendre. Sur le chemin, l'armée tâcherait d'établir des liens avec les Amérindiens et sèmerait le chaos en Caroline et en Virginie. Si le roi devait approuver ce projet, le commandement de l'armée et celui de la Louisiane devraient incomber à un général compétent. Il pense probablement à Montcalm, peut-être un peu à lui-même, soldat-philosophe à l'image de Xénophon ${ }^{70}$.

"Le projet n'est pas une chimère», insiste Bougainville, trahissant la crainte de ne pas être pris au sérieux. "Le projet exécuté serait glorieux à la nation et conserverait au Roi un bon corps de troupe. Les Français sont dignes de faire ce que les Grecs ont fait et la retraite des 10000 est un des traits qui a le plus immortalisé la Grèce ${ }^{71}$.» À nos yeux, un tel voyage paraît irréaliste, voire irréalisable ; il parut sans doute de même à ceux du secrétaire d'État à la Marine et de Louis XV, qui ne donnèrent apparemment jamais suite au mémoire. Certains biographes ont vu là la marque de la naïveté du jeune officier inexpérimenté et impatient, armé d'une connaissance théorique de la géographie nord-américaine plutôt que d'une véritable intuition de ses dimensions ${ }^{72}$.

Bien qu'il soit vrai que Bougainville manquait d'expérience, nous croyons que sa réappropriation de l'Anabase n'est pas une marque de naïveté.

69. Ibid., 33.

70. Ibid., 33.

71. Id.

72. C'est le cas de Kimbrough: «He seemed never to have fully comprehended the vast distances of America, the difficulties encountered in traversing them, or even the time required to do so. His proposal to fall back on Louisiana was absurd and highly impractical... Perhaps this was a quirk of character caused by that impatience which never fully deserted him, even in old age.» M. Kimbrough, Louis-Antoine de Bougainville..., op. cit., 11. 
Montcalm décrit Bougainville comme un jeune homme hardi, un peu trop peut-être: «Vous ne pourriez croire les ressources que je trouve en lui... Il se présente de bonne grâce au coup de fusil, article sur lequel il a plus besoin d'être contenu que d'être excité ${ }^{73}$.» Cette hardiesse qu'on lui prête nous donne matière à croire que Bougainville était pleinement conscient de l'audace de son plan, et qu'il l'envisageait sérieusement ${ }^{74}$. Évoquant Virgile, Bougainville note dans son journal que la situation requiert "activité et audace» et que «audaces fortuna juvat!» (la fortune sourit aux audacieux $)^{75}$. S' il sous-estime la distance séparant le Canada de la Louisiane, il envisage tout de même un périple hérö̈que sur une très longue distance ${ }^{76}$, les circonstances désespérées requérant des actions extraordinaires. Sa réappropriation de l'Anabase afin d'exalter l'armée française en Amérique du Nord, une comparaison objectivement insoutenable mais poétiquement efficace, ne trahit pas la naïveté de Bougainville; elle montre plutôt qu'il est inspiré par les événements.

$\mathrm{La}$ "gloire» de la France, une gloire semblable à celle dont les hommes de Xénophon furent couverts à leur retour en Grèce, voilà de quoi motiver Bougainville. Si le Canada capitule, l'armée française peut tout de même espérer se couvrir d'honneur en tentant une retraite glorieuse. Avec de la chance, elle pourra même faire face à l'ennemi en terrain avantageux et sauver, sinon le Canada, du moins la Louisiane. L'importance que Bougainville accorde à son projet a d'autant plus de sens si l'on tient compte du fait qu'il perçoit le contentieux entre Canadiens et Français, de même que la corruption des autorités coloniales, comme une grande source de honte pour la nation. Il semble qu'il ait envisagé cette retraite glorieuse comme une façon de redorer une réputation ternie.

Bougainville investit en outre plusieurs événements clés de la guerre d'une dimension épique. Sa description de l'arrivée in extremis des renforts

73. Louis-Joseph, Marquis de Montcalm, Journal du Marquis de Montcalm (Montréal, Michel Brûlé, 2007), 12 .

74. Qu'objectivement son projet ait été ou non une chimère a peu d'importance. Ce qui importe, c'est que Bougainville semble avoir cru qu'il ne l'était pas. Le fait qu'il fasse référence à son plan dans un mémoire ultérieur (L.-A. de Bougainville, $E C$, op. cit., 25, 34, 56) suggère qu'il le prenait au sérieux. D’ailleurs, il ne s'agit pas du seul projet ambitieux qu'il soumet à la Cour. En conjonction avec celui que nous avons décrit, il propose que la Couronne investisse massivement non pas directement dans la défense de la colonie, mais sous la forme d'une attaque surprise sur les côtes de la Caroline, afin de détourner l'attention de l'ennemi et semer la confusion. Les troupes ainsi débarquées pourraient ensuite retraiter vers la Louisiane, toujours dans l'idée de créer des alliances avec les Amérindiens, les esclaves et les colons allemands qu'il croit maltraités sur ces terres, Ibid., 55.

75. Ibid., 199, Aen. X: 284.

76. Ainsi l'officier écrit, en parlant de l'immensité du territoire: «Qu'on se représente 5 à 600 lieues de pays où l'on est sans cesse obligé de construire et de se retrancher. », Ibid., 25. 
du chevalier de Lévis à la veille du siège de Carillon, en est un bon exemple :

Entre 6 et $8 \mathrm{~h}$. du soir des piquets de nos troupes, détachés avec le Ch[evali] er de Lévis, arrivèrent au camp. Ils avaient fait la plus grande diligence, marchant jour et nuit malgré les vents contraires pour joindre leurs camarades qu'ils avaient su à la veille d'être attaqués, aussi furent-ils reçus de notre petite armée avec la même joye que les légions de César le furent par ces cohortes romaines bloquées avec Cicéron par un essaim de Gaulois. Le Ch[evali]er de Lévis arriva dans la nuit ${ }^{77}$.

L’arrivée de Lévis est décrite comme un exploit, une marche héroïque contre la montre et les éléments, motivée par le sens du devoir. À cet instant critique, tout aurait pu chavirer: "Dans cette occasion nous avons dû nous rappeler ce mot de César: "jusqu'à présent j'ai combattu pour la gloire mais aujourd'hui pour la vie"... Notre défaite entraînait la perte de la colonie ${ }^{78}$ ». Le "mode» de représentation épique s'étend ici à un événement et à des personnages réels.

\section{BOUGAINVILLE ORATEUR, SATIRISTE ET TRAGÉDIEN}

La critique que Bougainville adresse à l'administration canadienne mérite qu'on s'y attache, car si la corruption coloniale a été bien étudiée, on a peu cherché à l'examiner sous l'angle des dénonciateurs ${ }^{79}$. Guy Frégault décrit les mécanismes douteux par lesquels l'intendant Bigot et plusieurs de ses complices ont fait fortune au Canada, de même que les tenants et aboutissants de leur procès ${ }^{80}$. J. F. Bosher a soutenu quant à lui que la "corruption» au sens où nous l'entendons aujourd'hui était endémique à l'époque, parce que le système administratif de l'Ancien Régime, contrairement au nôtre, ne traçait pas de ligne précise entre l'intérêt privé et la fonction d'État; bien que les autorités aient été en mesure de juger de l'honnêteté d'individus, elles ne l'auraient pas fait en raison des organisations mal balisées ${ }^{81}$. Plus récemment, Louise Dechêne a rouvert le

77. Ibid., 277.

78. Ibid., 282.

79. Quelques biographes font exception à la règle, dont Kerralain, qui défend l'honneur de son ancêtre, et Ross, qui prend ouvertement parti pour Bougainville ( Bigot... was in fact the centre of a monstrous system of public fraud and malversation. »), M. Ross, Bougainville, op. cit., 29.

80. Guy Frégault, François Bigot, administrateur français (Montréal, Les Études de l'Institut d'histoire de l'Amérique française, 1948, 1968), 2 vol., 442 p. et 415 p.

81. J. F. Bosher, "Government and Private Interests in New France», Canadian Public Administration, 10,2 (1967): 246-248, 256. Voir aussi, du même auteur, "The French government's motives in the Affaire du Canada, 1761-1763", English Historical Review, 96,378 (1981): 59-78, où Bosher s'intéresse entre autres 
dossier dans son étude sur le pouvoir des institutions de la colonie dans la gestion des subsistances, où l'historienne distingue nettement entre les dernières années du Régime français, riches en occasions d'enrichissement, et les décennies précédentes. Nuançant l'analyse de Bosher, elle démontre qu'entre la notion de service public et celle du péché véniel ou mortel, l'Ancien Régime possédait bien les moyens de faire hésiter ses serviteurs trop enclins à confondre les deniers du roi et les leurs ${ }^{82}$.

Il n'est donc pas surprenant que la corruption aiguë qui sévit au Canada dans les années 1750 frappe l'esprit de Bougainville. On est cependant en droit de se demander si l'omniprésence du phénomène, particulièrement dans le domaine du ravitaillement qui s'effectue, pour ainsi dire, sous les yeux de l'officier, suffit à expliquer l'indignation et la colère dont est empreint son témoignage. S'il est vrai que sa condescendance envers les «colonistes» qui gouvernent ou commandent (condescendance assez commune chez les Français métropolitains de l'époque) fournit une partie de la réponse, son appréciation négative des administrateurs de la colonie mérite d'être réexaminée. Sa représentation de la colonie, de façon analogue à celle du Sauvage ou de sa propre personne, n'est pas imputable qu’à ses préjugés ou qu'à sa naïveté. Notre examen montre que l'indignation de Bougainville est motivée non pas seulement par les irritants du rationnement et les rumeurs de complot $^{83}$, mais aussi par les modèles littéraires de l'Antiquité classique - harangue, satires et tragédies - qu’il emploie dans sa critique de l'administration coloniale.

Bougainville dirige ses attaques sur deux fronts, soit la corruption et l'incompétence des deux "méchants» du drame qu'il documente. En premier lieu vient l'accusation de corruption contre l'intendant François Bigot (1755-1760), sa clique d'officiers civils et ses commandants de fort déployés tout au long des postes de traite de la Nouvelle-France. Vols, monopoles abusifs, faux noms, traitements préférentiels, dépenses injus-

aux motivations cachées du gouvernement français dans la mise en place de ce procès qu'il qualifie d'injuste. Sans défendre Bigot et ses complices, il relativise leurs torts et soutient qu'on a fait d'eux des boucs émissaires responsables des défaites militaires comme de la faillite de l'État. En effet, pour quelle raison une administration corrompue, et reconnue comme telle depuis des années par des instances supérieures qui l'étaient tout autant, aurait soudainement mérité un procès de la sorte, sinon parce que l’État y trouvait des avantages politiques et économiques?

82. Louise Dechêne, Le partage des subsistances au Canada sous le régime français (Montréal, Éditions du Boréal, 1994), 136-139.

83. Dechêne affirme que «bon nombre [des officiers] partagent les croyances populaires sur les magasins remplis de vivres appartenant aux gens en place, lesquels attendent que la famine augmente pour les vendre aux habitants et au roi», en plus de voir un "complot contre le roi et son armée» dans tout le gaspillage et le chaos logistique «qui gênent le mouvement des troupes», ibid., 181. 
tifiées, distribution inadéquate de la nourriture et des marchandises, inflation artificielle des prix pour les commodités de base, autant d'irrégularités qui scandalisent Bougainville: "C'est à la justice criminelle à jouer ici son rôle ${ }^{84}$.» Le jeune officier anticipe ainsi l'Affaire du Canada de 1763, où Bigot et 53 de ses acolytes furent convoqués au Châtelet de Paris et trouvés coupables, à divers degrés, de vols, de fraudes fiscales et d'autres irrégularités financières ${ }^{85}$.

Lorsqu'ils n'en étaient pas directement «victimes», les officiers français étaient témoins de la corruption qui sévissait dans la colonie. Dans les Écrits, on compte un grand nombre de reproches adressés aux administrateurs coloniaux canadiens et français, de même qu'aux soldats, marchands et autres professionnels et artisans suivant leur exemple. Dans le climat de tension politique qui se développe autour des quartiers généraux de Montcalm au fil des ans, Bougainville imagine peu à peu une conspiration que la moindre irrégularité, la moindre erreur stratégique tend à confirmer.

Dans l'intimité relative de son journal, Bougainville assume ainsi le rôle d'un Cicéron, républicain vertueux dénonçant la corruption et tentant de sauver la nation du désastre. L'ouverture catilinienne "O tempora, o mores» devient "Quel pays! Quelle guerre $!^{86}$ " Le mal est si profond que presque tous y trouvent leur part de responsabilité : «Si les gens en place tolèrent de pareils abus, décisifs pour la perte de la colonie, il faut qu' ils leur soient profitables: s'ils les ignorent, pourquoi sont-ils en place ${ }^{87}$ ?" Ainsi, Bougainville considère comme ennemis de la France les Canadiens qui bénéficient de traitements préférentiels de la part de l'administration coloniale et qui, comme leurs leaders, font preuve d'ingratitude et d'avarice : «Remarquez comme ici tout est dirigé ad majus lucrum $!^{88}$ " Le mépris que Bougainville ressent face à l'argent, bien qu'il fasse écho à l'opinion

84. L.-A. de Bougainville, EC, op. cit., 298.

85. Il est dommage que nous n'ayons pas l'opinion de Bougainville sur l'Affaire du Canada. Si l'on en croit Bosher, un philosophe aurait eu de quoi être scandalisé par l'injustice du procès, "Government and Private Interests ", op. cit., 60-61.

86. L.-A. de Bougainville, $E C$, op. cit., 270. Comparez avec la huitième section du journal de Montcalm (1759), écrite de la main d'un officier subalterne non identifié et connaissant ses classiques. L'exercice est intéressant parce qu'il révèle une invective cicéronienne semblable à celle de Bougainville, mais qui ne serait cependant pas de lui. Voir commentaire de Roger Léger (d'après les notes de Léon Lecestre), "Avant-propos», Journal du Marquis de Montcalm en Canada de 1756 à 1759. Édition originale revue et augmentée (Montréal, Michel Brulé, 2007), 27.

87. L.-A. de Bougainville, EC, op. cit., 296.

88. Ibid., 297. 
populaire sur les marchands ${ }^{89}$, rappelle celui qu'affichent tant d'auteurs classiques associant la vertu morale à la simplicité, et la dépravation au luxe. Par le ton et par la forme, Bougainville s'insère, à l'instar de Montaigne et Montesquieu, dans la tradition d'humanisme civique qui éclôt durant la Renaissance ${ }^{90}$.

Tout compte fait, on ne saurait imputer la perte de la colonie aux abus de Bigot. Le dénouement de la guerre de Sept Ans releva des décisions politiques et économiques de la Cour avant et pendant le règlement des termes de 1763 , dans un contexte de crise financière ${ }^{11}$. Cependant, aux yeux de Bougainville, la corruption endémique annonce une défaite imminente: «Il est donc bien vrai de dire que ce pays périra après avoir ruiné la France par le monstrueux abus des privilèges exclusifs ${ }^{92}$. " Non seulement des fraudeurs ruinent la colonie; ils ruinent du même coup la métropole chargée de la défendre. L'ampleur du cancer est telle que l'officier a peine à y croire: "On serait souvent obligé de s'interrompre pour avertir que ce qui n'est pas vraisemblable est souvent vrai, et l'est presque toujours dans ce pays ${ }^{93}$." Souvent dépassé par des circonstances invraisemblables, Bougainville l'orateur républicain se fait satiriste, ventilant alors son cynique et son sarcasme.

En effet, Bougainville ne peut s'empêcher d'échapper çà et là des remarques teintées d'humour noir, qui traduisent bien son incrédulité et son indignation. Il réfère directement à la satire à au moins deux reprises, la première dans une citation qu'il attribue à Bayle: «Il est malheureux que les hommes soient tels qu'en écrivant l'histoire on ait l'air de faire une satyre $^{94}$ »; et plus loin, à Juvénal: «Difficile est satyram non scribere ${ }^{95}$. » [Il est difficile de ne pas écrire une satire]. Ici comme ailleurs, ce n'est pas un

89. L. Dechêne, Le partage des subsistances..., op. cit., 176-177.

90. La Stanford Encyclopedia of Philosophy définit l'humanisme civique en ces termes: "Civic humanism is linked in principle to a classical educational program that goes beyond the formative capacity of participatory citizenship itself and involves the conscious revival of ancient ideals. Republican candor, simplicity of manner, opposition to ostentation, luxury and lucre, are common, though not universal republican themes. Some theorists also dwell on the millenarian aspirations associated with republican ideals responding to the fragility of the republic and the need to provide against its corruption and decay with the passage of time." Athanasios Moulakis, "Civic Humanism», The Stanford Encyclopedia of Philosophy (Fall 2008 Edition), Edward N. Zalta (dir.), http:/ / plato.stanford.edu/archives/fall2008/entries/ humanism-civic/ [consulté le 30 mars 2011]. À titre comparatif, voir Andrew Fitzmaurice, Humanism and America: An Intellectual History of English Colonisation, 1500-1625 (Cambridge, Cambridge University Press, 2003) $216 \mathrm{p}$.

91. J. F. Bosher, "Government and Private Interests... », op. cit., 70-71.

92. L.-A. de Bougainville, EC, op. cit., 299.

93. Ibid., 292.

94. Ibid., 282.

95. Ibid., 300 (Juvenal, Satires I). 
accident si les portraits satiriques qu'il peint des officiers de la colonie et de leurs protégés sont généralement accompagnés par des références classiques: "Quand je réfléchis sur la façon dont est gouverné ce pays pour lequel le Roi fait des dépenses énormes, je me rappelle celle dont Jupiter gouverne le monde, décrite dans le banquet de Lucien ${ }^{96}$.» $\mathrm{Ou}$ encore: "Titus disait qu'il avait perdu sa journée, quand il l'avait passé sans accorder un bienfait. Un Européen ici a bien employé la sienne quand il l'a passé sans apprendre une concussion ou friponnerie nouvelle ${ }^{97}$.» L'adaptation de ces "classicismes» aux circonstances spécifiques qu'il commente témoigne de la culture philosophique de l'auteur.

C'est principalement la satire qui porte sa critique de l'incompétence du marquis de Vaudreuil, le gouverneur général de la colonie (1755-1760). Supérieur immédiat de Montcalm, premier gouverneur général né au Canada, Vaudreuil sert le roi en tant que son représentant officiel. Il est le chef des armées en Nouvelle-France et le principal négociateur sur le plan de la politique extérieure et des «affaires indiennes». Il fait en outre l'objet de sévères critiques de la part du jeune officier irrité par son irrésolution et ses priorités mal placées. Le portrait de Vaudreuil dans les Écrits de Bougainville est souvent ironique, grotesque, parodique. Tantôt montré comme un leader faible et hésitant, tantôt comme un Don Quichotte amoureux de ses chimères, il paraît borné au point de nuire à ceux qui risquent leur vie pour la colonie $e^{98}$. Par une allusion mythologique efficace, Bougainville en fait la caricature: «V[audreuil] quand il a conçu une idée en devient amoureux comme Pygmalion le devint de sa statue. Je le pardonne à ce dernier, car elle était un chef-d'œuvre ${ }^{99}$. " Il lance aussi ses dards à l'endroit des Canadiens embauchés par le gouverneur pour compléter des travaux visant à faciliter le ravitaillement des troupes: «Mr. de Vaudreuil avait envoyé pour diriger les travaux du chemin un sculpteur de Montréal. Je doute que Phidias eût bien fait un chemin mais comme le sculpteur est retourné à son premier métier, ces travaux ont cessé ${ }^{100}$.» L'incompétence est un art que maîtrisent autant l'employeur que ses employés!

L'exaspération de Bougainville naît de l'intrusion d'amateurs là où seuls les professionnels devraient avoir leur mot à dire. À son grand déplaisir,

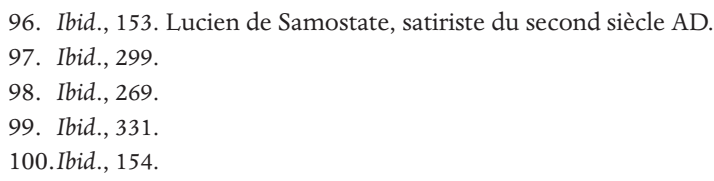


il constate que «maintenant que la guerre s'établit sur le pied européen... bourgeois, financiers, marchands, officiers, évêques, curés, jésuites, tout cela projette, disserte, parle, reparle, prononce ${ }^{101}$ ». Il discerne dans cette fâcheuse tendance les germes de futurs désastres: "Grand malheur pour ce pays; il périra victime de ses préjugés, de sa confiance aveugle, de la stupidité ou de la friponnerie de ses chefs. Cet oracle est plus sûr que celui de Calchas ${ }^{102}$. » Frustré par ces Canadiens qui dévalorisent les victoires de l'armée française pour exalter leur propre contribution ("Quelques gens disaient que les Anglais avaient laissé prendre ce fort exprès; subtilité aussi ridicule que celle des Athéniens qui doutèrent si le roi Philippe ne s'était pas laissé mourir exprès pour les tromper $\left.{ }^{103} \cdot »\right)$, Bougainville riposte avec sarcasme: «Facilité de cette expédition suivant le peuple, le M[arqu]is de V[audreuil] et l'évêque qui l'eût pris, disait-il, avec son clergé; sans doute comme Josué prit Jéricho en faisant trois fois le tour des murs ${ }^{104}$.

Si ce n'était des répercussions «néfastes» sur l'armée française, ce cirque frôlerait le comique ${ }^{105}$. Aussi, Bougainville rapporte une admonestation que M. de Rigaud, frère du marquis de Vaudreuil, aurait adressée à Montcalm après que ce dernier eut suggéré que des Français fussent dépêchés au lieu des Canadiens pour négocier avec les Amérindiens: " [C]'est un attentat contre les droits de la colonie; envoyer un off[ici]ier français avec des Sauvages, c'est Catilina qui se déguise en femme pour pouvoir entrer dans les mystères de la bonne déesse ${ }^{106}$.» Ces mots, que Bougainville met dans la bouche de Rigaud, marquent un renversement des rôles ironiques, par lequel il illustre l'entêtement ridicule, mais tragique, des administrateurs coloniaux. En effet, on peut supposer qu'à ses yeux, le rôle du Catiline efféminé que Rigaud assigne à Montcalm conviendrait mieux à Bigot ou à Vaudreuil.

Bougainville impute la chute de la colonie à la corruption de Bigot et Vaudreuil au moins autant qu'aux assauts de l'armée britannique : «Aussi écrit-on de Québec qu'un grand nombre de familles se sauvent en France: je dis "se sauvent", parce qu'il s'agit ici de fuir un ennemi plus dangereux

101. Ibid., 294.

102. Ibid., 294. Notez ici un bon exemple de référence aux oracles de l'Antiquité qui va au-delà de l'expression du scepticisme de Bougainville face aux superstitions. On constate un changement notable du motif, où, ironiquement, le scepticisme face aux oracles cède sa place à la frustration causée par la surdité de ceux à qui il adresse ses prédictions. Bougainville devient une sorte de Cassandre.

103. Ibid., 331.

104. Ibid., 331.

105. Ainsi, l'officier compare, dans son langage hyperbolique, le traitement que Vaudreuil réserve aux Français avec la façon dont les Lacédémoniens traitaient les Ilotes, Ibid., 154.

106. Ibid., 304. 
mille fois que les Anglais ${ }^{107}$.» Dans ses notes du $1^{\text {er }}$ au 10 octobre 1758 , Bougainville ne rit plus ${ }^{108}$. La satire cède la place à la tragédie, voire à l'élégie, par laquelle il exprime son profond découragement face à un mal trop grand pour être arrêté. La chute de la colonie, Bougainville se la représente dans un cadre plus large, celui de la dépravation morale et de l'affaiblissement d'un peuple. Gardons en tête qu'en 1758, tandis qu'en Amérique le vent tourne peu à peu en faveur des Britanniques et qu'on sait la famine imminente, des nouvelles tout aussi sombres arrivent d'Europe, annonçant les défaites de la France sur le continent. Ce contexte ajoute au désespoir de Bougainville:

Notre marine est donc écrasée, la discipline militaire bannie de nos armées; le découragement a flétri nos courages, nous n’avons plus de généraux, car ce n'est pas en les changeant tous les jours qu'ils deviendront meilleurs; ' l'intrigue de cour et de cabinet a donc pris seule le timon des affaires. Talens, vues, résolutions, vertus, projets sages et décisifs, c'en est fait, la France ne vous connaît plus; elle ne devra plus son salut qu'à quelques hasard heureux; mais sa gloire, sa gloire qui la lui rendra?... Mais hélas! je le dis dans l'amertume de mon cœur, désir de gloire, délicatesse de sentimens, émulation, honneur, qu'êtes vous devenus? / Notre âme est avilie; un vil intérêt est seul le moteur et l'objet de notre conduite. On rougirait presque de faire une belle action, uniquement pour la gloire de l'avoir faite ${ }^{109}$.

Bougainville cherche à convaincre son lecteur que c'est la gloire de la Nation qui est en jeu, que la cupidité de certains individus, parce que contagieuse, menace de déshonorer la France. Bien qu'on ne puisse pas retracer une source d'inspiration spécifique au ton et au propos de ce passage, l'anticipation de la défaite qu'il met en scène est sans l'ombre d'un doute investie d'une charge tragique qui colore les «faits» rapportés dans le journal de campagne.

Bougainville n'interprète pas les événements dont il est le témoin d'une façon naïve, au travers du filtre de ses préjugés, mais utilise différents «modes» d'expression pour soutenir sa critique de l'administration coloniale. Par des appels à diverses sources classiques, il assume tour à tour le rôle et la droiture d'un Cicéron, tire profit de l'ironie et du sarcasme comme un satiriste et renforce son témoignage en faisant appel au registre tragique; cela faisant, il formule une critique des institutions et des officiers de la colonie analogue à celle de ses contemporains philosophes. La

107. Ibid., 321.

108. Ibid., 317-322.

109. Ibid., 318-322. 
contribution principale de cette discussion est donc d'ancrer la partialité que l'on reproche parfois à Bougainville dans son humanisme civique inspiré des valeurs de l'Antiquité classique, de même que dans son désir conscient de dramatiser son propos. Bougainville n'écrit pas en chroniqueur ou en journaliste, mais en philosophe et en dramaturge.

\section{CONCLUSION}

Au travers des Écrits, Bougainville fait appel à différents genres littéraires. L'histoire naturelle et morale, la critique ethnographique, le récit épique, la harangue, la satire et la tragédie font surface dans son témoignage sous la forme de "classicismes» qui colorent sa représentation des Amérindiens, exaltent sa représentation de lui-même et celle de l'armée française, et donnent du mordant à son plaidoyer contre la corruption coloniale. En tant qu'officier, Bougainville est le témoin direct des événements de la guerre de Sept Ans, mais en tant qu'auteur humaniste, il participe à sa façon au projet critique des philosophes. Il s'agit donc d'expliciter la rhétorique de l'auteur, sans quoi l'on risque d'accorder trop ou trop peu d'importance à ce que les uns appelleront des ornements, et les autres, des indicateurs fiables de son expérience de la colonie. Une évaluation du témoignage de cet officier cultivé requiert que l'on identifie les modes d'expression qui en colorent le contenu, et qu'on s'intéresse de plus près aux lectures qui ont nourri son imagination.

Il convient de se demander en quoi cette étude, au-delà du correctif qu'elle apporte au portrait de Bougainville, peut être utile à l'historien. Louise Dechêne a critiqué l'historiographie nationaliste et militaire de la Nouvelle-France pour s'être trop peu méfiée des représentations du peuple canadien produites par les élites de passage dans la colonie ${ }^{110}$. C'est à l'histoire sociale, d'après elle, de s'aventurer sur le champ de bataille, afin de contourner la rhétorique des discours officiels et d'aborder la réalité coloniale ${ }^{111}$. Notre approche est complémentaire. Plutôt que de contourner la rhétorique de Bougainville, nous avons tâché de la confronter pour la tirer au clair. À d'autres d'adopter ou non cet outil au moment d'évaluer le témoignage de l'auteur. Certes, Bougainville est un cas d'espèce; mais dans la mesure où sa culture littéraire est représentative de celle des autres privilégiés - métropolitains et coloniaux - dont la

110. L. Dechêne, Le peuple..., op. cit., 58-59.

111. Ibid., 61-91. 
plume collective a façonné l’image du Canada sous le Régime français, une étude plus systématique de ce bagage intellectuel s'impose ${ }^{112}$.

112. J'aimerais remercier tous ceux et celles qui m’ont accompagné durant la préparation de ce travail, en particulier mes mentors du Collège d'éducation humaniste de l'Université Concordia et ceux du Département d'histoire des sciences de l’Université Johns Hopkins. Un merci spécial à Thomas Wien, pour son support et ses judicieux conseils. 